\title{
Identificação de espécies de Fusicoccum causadoras de podridão em frutos de abacate
}

\author{
Ana Carolina Firmino ${ }^{1}$, Ivan Herman Fischer ${ }^{2}$, Hugo José Tozze Júnior ${ }^{3}$, Daniel Dias Rosa ${ }^{4}$ Edson Luiz Furtado ${ }^{4}$
}

\begin{abstract}
${ }^{1}$ Universidade Estadual Paulista Júlio de Mesquita Filho, Faculdade de Ciências Agrárias e Tecnológicas, Rod. Cmte João Ribeiro de Barros, km 651 - Bairro das Antas, Dracena, São Paulo. ${ }^{2}$ Agência Paulista de Tecnologia dos Agronegócios, Polo Regional Centro Oeste, Av. Rodrigues Alves, n.40, 17030-000, Bauru, São Paulo. ${ }^{3}$ Coordenadoria de Defesa Agropecuária, Secretaria de Agricultura e Abastecimento, R. Campos Sales, n.507, 13400-200, Piracicaba, São Paulo. ${ }^{4}$ Universidade Estadual Paulista Júlio de Mesquita Filho, Faculdade de Ciências Agronômicas, Rua José Barbosa de Barros, n.1780, CEP 18610-307, Botucatu, São Paulo.
\end{abstract}

Autor para correspondência: Ana Carolina Firmino (anacarfir@gmail.com)

Data de chegada: 14/11/2014. Aceito para publicação em: 26/08/2015.

$10.1590 / 0100-5405 / 2051$

\section{ABSTRACT}

Firmino, A.C.; Fischer, I.H; Tozze Júnior, H.J.; Rosa, D.D.; Furtado, E.L. Identification of Fusicoccum species causing rot in avocado fruits. Summa Phytopathologica, v.42, n.1, p.100-102, 2016.

The Fusicoccum genus of fungi are known to cause stem-end rot in various fruit plants, such as mango, guava, peach and avocado. Several species of this fungus are reported attacking avocado (Persea americana) in several countries. Based on this information, the present study aimed to identify species of Fusicoccum associated with rot in avocado fruits in the State of São Paulo. Samples were collected (fruits with rot symptoms) from regions of Bauru, Bernadino de Campos and Piraju. All isolates obtained had its pathogenicity confirmed by inoculation of healthy avocado fruits. After confirming its pathogenicity, these isolates had their DNA extracted and the ITS-5.8S rDNA region was amplified. After editing, these sequences were used to search for similar sequences in the NCBI. Eleven samples were identified as Neofusicoccum parvum and others were identified as Botryosphaeria dothidea ( $F$. aesculi). Both species were found in all regions of collection.

Keywords: characterization, fungus, postharvest, Persea americana

\section{RESUMO}

Firmino, A.C.; Fischer, I.H; Tozze Júnior, H.J.; Rosa, D.D.; Furtado, E.L. Identificação de espécies de Fusicoccum causadoras de podridão em frutos de abacate. Summa Phytopathologica, v.42, n.1, p.100-102, 2016.

Fungos do gênero Fusicoccum são conhecidos por causarem podridão peduncular em várias frutas, como manga, goiaba, pêssego e abacate. Diversas espécies deste fungo são relatadas como patogênicos ao abacate (Persea americana) em diversos países. Com base nesta informação, o presente trabalho teve o objetivo de identificar espécies de Fusicoccum relacionadas com podridão em frutos de abacateiro no Estado de São Paulo. Foram coletadas amostras (frutos apresentando podridão) das regiões de Bauru, Bernadino de Campos e
Piraju. Todos os isolados obtidos tiveram sua patogenicidade confirmada através de inoculação em abacates sadios. Após a confirmação de sua patogenicidade, estes isolados tiveram seu DNA extraído e a região ITS-5.8S rDNA foi amplificada. Após edição, estas sequências foram utilizadas para procurar sequências similares no NCBI. Onze amostras foram identificadas como $N$. parvum e as outras foram identificadas como Botryosphaeria dothidea ( $F$. aesculi). Ambas as espécies foram encontradas em todas as regiões de coleta.

Palavras-chave: caracterização, fungo, pós-colheita, Persea americana

O abacateiro (Persea americana Mill.) é uma fruteira tropical, da família Lauraceae, originária do continente americano, tendo o México e a Guatemala como centros de diversidade (6). O Brasil é um dos maiores produtores de abacate do mundo, sendo São Paulo o principal Estado produtor, com 94.294 toneladas em 2013 (11). Para exportação, as variedades mais cultivadas são a Hass e a Fuerte, conhecidas popularmente como 'avocado'.

Diversas doenças ocorrem ou manifestam-se tanto em pré como em pós-colheita do abacate. As doenças de pós-colheita, também conhecidas como podridões de frutos, depreciam e até inviabilizam o consumo do fruto. Dentre os diversos fungos que são associados com problemas pós-colheita do abacate podem-se citar aqueles pertencentes ao gênero Fusicoccum, que engloba várias espécies de fungos responsáveis por causar podridão peduncular em frutos em diversos lugares do mundo $(5,13,15)$.

O presente trabalho teve o objetivo de identificar as espécies de
Fusicoccum relacionadas com podridão em frutos de abacateiro no Estado de São Paulo. Foram coletadas amostras de frutos 'Hass' e 'Fuerte' em um "packinghouse" localizado na cidade de Bauru-SP. Estes frutos foram originários das seguintes cidades do Estado de São Paulo: Bauru, Bernadino de Campos e Piraju. Os frutos coletados foram individualizados em bandejas plásticas e submetidos à câmara úmida por 24 horas, visando favorecer a ocorrência de patógenos em estádio latente, permanecendo por mais 14 dias a $25^{\circ} \mathrm{C}$ e $70-75 \%$ de umidade relativa (UR). Realizou-se o isolamento em meio de cultura batata-dextrose-ágar (BDA) dos fungos relacionados aos sintomas de podridões nos abacates.

Todos os isolados que mostraram características culturais e morfológicas típicas de Fusicoccum tiveram sua patogenicidade confirmada através de inoculação em frutos sadios de abacate 'Hass'. Utilizou-se como inóculo disco de meio BDA com 6 mm de diâmetro contendo estruturas do fungo proveniente das extremidades de colônias 
cultivadas por 5 dias sob luz contínua a $25 \pm 1{ }^{\circ} \mathrm{C}$. A inoculação foi realizada pela deposição de um disco no centro de frutos previamente desinfetados com álcool (70\%) e hipoclorito de sódio $(0,5 \%)$ e feridos com furador de $6 \mathrm{~mm}$ esterilizado. A incubação dos frutos foi realizada no escuro, a $25 \pm 1{ }^{\circ} \mathrm{C}$ e $70-75 \%$ de UR, por sete dias.

$\mathrm{O}$ experimento foi conduzido em delineamento inteiramente casualizado com quatro repetições por tratamento. Frutos inoculados apenas com disco de meio BDA não colonizado foram utilizados como testemunha. Ao final do experimento, os diâmetros perpendiculares das lesões foram mensurados com paquímetro.

Após a confirmação de sua patogenicidade, os isolados de Fusicoccum obtidos tiveram seu DNA extraído e a região ITS-5.8S rDNA foi amplificada (oligonucleotídeos ITS1/ITS4) (17). Após edição, estas sequências foram utilizadas para procurar sequências similares no NCBI (National Center for Biotechnology Information). As sequências obtidas foram alinhadas e editadas no programa Bioedit (10). A árvore filogenética foi processada com o programa Mega 5.05 utilizando o método "jukes-cantor" para a construção da matriz de distâncias, pelo método de Neighbor-Joining (12). Foi realizado um "bootstrap" com 10.000 replicações.

Foram obtidos 15 isolados com características culturais e morfológicas típicas de Fusicoccum (Tabela 1 e Figura 1) (3). Como pode ser observado na tabela 1 , todos os isolados foram patogênicos, causando necrose escura que evoluiu para todo o fruto, com produção de micélio acinzentado na superfície do fruto necrosado. Em levantamento das podridões em abacates 'Hass' no estado de São Paulo, Fischer e colaboradores (8) apontam incidência de 3\% de frutos atacados somente com Fusicoccum. Porem apesar de baixa incidência esta doença pode, quando em associação com outras doenças, como antracnose, causar perdas relevantes, pois potencializa a decomposição dos frutos infectados $(4,9)$. As infecções ocorrem no campo através das lenticelas e ferimentos e geralmente tornam-se ativas após a colheita

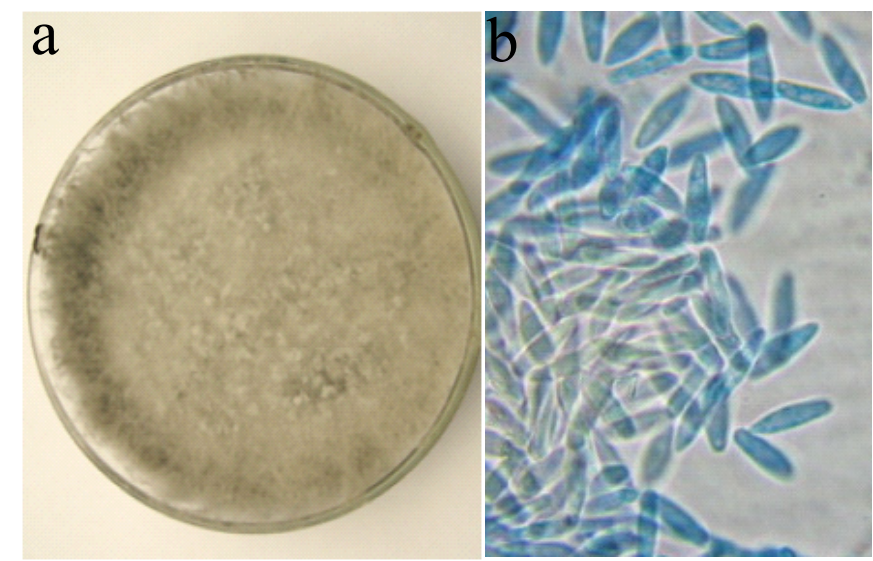

Figura 1. Detalhe da colônia (a) e dos conídios (b) dos isolados de Fusicoccum obtidos de abacate

e amolecimento do fruto (16).

Das 15 amostras seqüenciadas, 11 foram identificadas como Neofisicoccum parvum e as outras foram identificadas como Botryosphaeria dothidea (F. aesculi) (Figura 2). Ambas as espécies foram encontradas em todas as regiões de coleta (Tabela 1). Ambos os fungos já foram relatados em plantas de mangueiras no Brasil causando podridões pós colheita, ocorrendo principalmente em regiões produtoras de manga do Submédio do Vale do São Francisco $(2,1)$.

Outras espécies de Botryosphaeria ( $N$. luteum e N. mangiferae), juntamente com as espécies de fungos encontradas no trabalho, já foram relatadas causando podridão em abacate, na Califórnia e em Taiwan $(14,16,7)$.

O trabalho permitiu identificar uma espécie de Neofisicoccum parvum e uma de Botryosphaeria dothidea (F. aesculi) causando podridão pós-colheita em frutos de abacateiro.

Tabela 1. Características dos isolados de Fusicoccum obtidos de abacate no Estado de São Paulo

\begin{tabular}{|c|c|c|c|}
\hline Isolado & Tamanho da Lesão* & Origem/Cultivar & Espécie \\
\hline A08 & 32,2 & Bauru-Fazenda Jaguacy/Fuerte & F. parvum \\
\hline B08 & 31,3 & Bauru-Fazenda Jaguacy/Fuerte & F. aesculi \\
\hline D08 & 25,5 & Bauru-Fazenda Jaguacy/Fuerte & F. parvum \\
\hline E08 & 22,7 & Bauru-Fazenda Jaguacy/Fuerte & F. parvum \\
\hline F08 & 27,7 & Bernadino de Campos-Faz. Santa Cecília/Hass & F. parvum \\
\hline AG08 & 25,7 & Bernadino de Campos-Faz. Santa Cecília/Hass & F. aesculi \\
\hline H08 & 28,8 & Bernadino de Campos-Faz. Santa Cecília/Hass & F. aesculi \\
\hline I08 & 36,5 & Bernadino de Campos-Faz. Santa Cecília/Hass & F. parvum \\
\hline A11 & 55,7 & Piraju/Hass & F. parvum \\
\hline B11 & 8,2 & Piraju/Hass & F. aesculi \\
\hline D11 & 55,4 & Piraju/Hass & F. parvum \\
\hline E11 & 54,1 & Bernadinho de Campos-Faz. Santa Elisa/Hass & F. parvum \\
\hline G11 & 33,7 & Bernadinho de Campos-Faz. Santa Elisa/Hass & F. parvum \\
\hline I11 & 35,1 & Bauru-Fazenda Jaguacy/Hass & F. parvum \\
\hline $\mathrm{J} 11$ & 56,0 & Bauru-Fazenda Jaguacy/Hass & F. parvum \\
\hline
\end{tabular}

*Media de quatro repetições dos diâmetros $(\mathrm{mm})$ da lesão em frutos de abacate inoculados e avaliados após sete dias a $25^{\circ} \mathrm{C}$ e $75 \%$ de UR. 


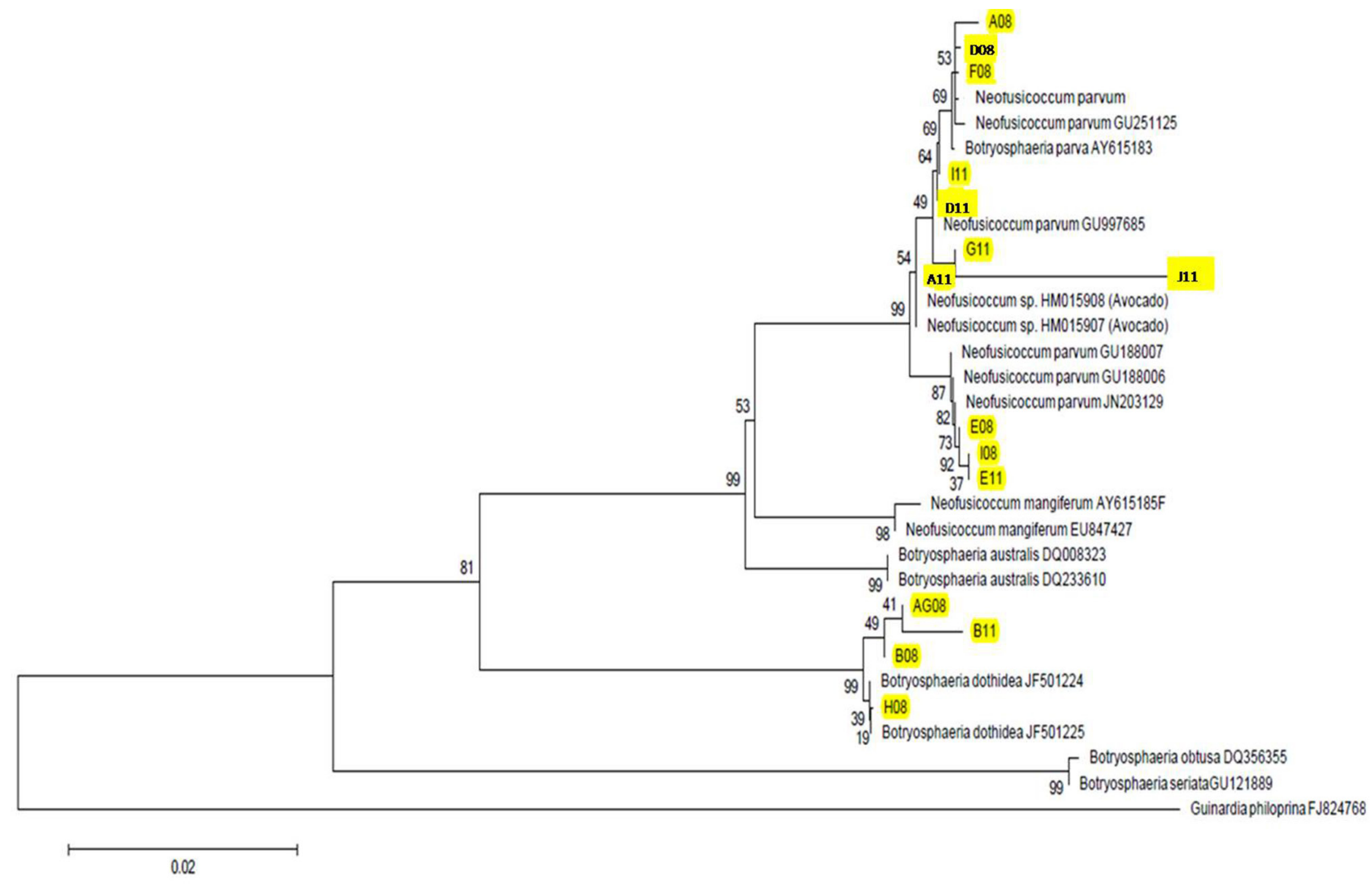

Figura 2. Árvore filogenética dos isolados de Fusicoccum de abacate processados pelo programa Mega 5.05 utilizando o método "jukes-cantor" para a construção da matriz de distâncias, pelo método de Neighbor-Joining ("bootstrap" com 10.000 replicações).

\section{AGRADECIMENTOS}

Os autores agradecem a FAPESP (2011/05710-0) e ao CNPq pelo apoio financeiro e a empresa Jaguacy Brasil Comércio de Frutas Ltda. pela doação dos frutos de abacate.

\section{REFERÊNCIAS}

1. Batista, D. C.; Lima, M. F.; Magalhães, E. E.; Júnior, E. F. A. Deteç̧ão de infecções quiescentes de fungos em frutos de mangueira. In: CONGRESSO BRASILEIRO DE FITOPATOLOGIA, 40., 2007, Maringá. Anais... Maringá: Sociedade Brasileira de Fitopatologia, 2007. p. 244.

2. Costa, V.S.O.; Michereff, S.J.; Martins,R.B.; Gava, C.A.T.; Mizubuti, E.S. G.; Camara, M.P.S. Species of Botryosphaeriaceae associated on mango in Brazil. European Journal of Plant Pathology, Dordrecht, v.127, n.4, p.509-519, 2010.

3. Crous, P.W.; Slippers, B.; Wingfield, M.J.; Rheeder, J.; Marasas, W.F.O.; Phillips, A.J.L.; Alves, A.; Burgess, T.; Barber, P.; Groenewald, J.Z. Phylogenetic lineages in the Botryosphaeriaceae. Studies in Mycology, Utrecht, v. 55, n. 1, p. 235-253, 2006.

4. Darvas, J.M. Stem end rot and other postharvest diseases. South African Avocado Growers' Association Yearbook, 2:49-51, 1978.

5. Darvis, J.M. Preharvest chemical control of the postharvest diseases of Fuerta avocados. South African Avocado Growers' Association Yearbook, 5:56-57, 1982.

6. Donadio, L.C. Abacate para exportação: aspectos técnicos da produção. $2^{\mathrm{a}}$ ed. Brasília, EMBRAPA - SPI. 1995. 53P. (Série Publicações Técnicas FRUPEX, n.2)

7. Eskalen, A.; Mcdonald, V. Geographical Distribution of Botryosphaeriaceae and Phomopsis/Diaporthe Canker Pathogens of Avocado in California, 2010. Disponível em < http://www.avocadosource.com/cas_yearbooks/ cas 93 2010/cas 2010 v93 pg 087-098.pdf> Acesso em : 10 de Nov.
2014.

8. Fischer, I.H.; Tozze Júnior, H.J.; Arruda, M.C.; Massola Júnior, N.S. Pós-colheita de abacates Fuerte e Hass: características físicas e químicas, danos e controle de doenças. Semina: Ciências Agrárias, Londrina, v.32, p.209-220, 2011.

9. Freire, F.C.O.; Viana, F.M.P.; Cardose, J.E.; Santos, A.A. Novos hospedeiros do fungo Lasiodiplodia theobromae no estado do Ceará. Fortaleza: Embrapa Agroindústria Tropical, 2004. (Comunicado Técnico 91)

10. Hall, T.A. BioEdit: a user-friendly biological sequence alignment editor and analysis program for Windows 95/98/NT. Nucleic Acids Symposium Series, Oxford,. v. 41, p. 95-98, 1999.

11. IEA - Instituto de Economia Agrícola do Estado de São Paulo. Disponível em < http://ciagri.iea.sp.gov.br> Acesso em: 10 de Nov. 2014

12. Jukes, T. H; Cantor, C. R . Evolution of protein molecules. In: Munro, H N. (Ed.). Mammalian Protein Metabolism,. New York: Academic Press, 1969, p. 21-132.

13. Muirhead, I.F.; Fitzell, R.D.; Davis, R.D.; Peterson, R.A. Post-harvest control of anthracnose and stem-end rots of Fuerte avocados with prochloraz and other fungicides. Australazian Journal of Experimental Agriculture and Animal Husbandry, Melbourne, v.22, p.441-446, 1982.

14. Ni, H.F.; Liou, R.F.; Hung, T.H.; Chen, R. S.; Yang, H.R. First report of a fruit rot disease of avocado caused by Neofusicoccum mangiferae. Plant Disease, New York, v.93, n.7, p.760-760, 2009.

15. Pegg, K.G.; Coates, L.M.; Korsten, L.; Harding, R.M. Foliar, fruit and soil diseases. In: Whiley, A.W.; Schaffer, B.; Wolstenholme, B.N. (Eds.). The avocado: botany, production and uses. CAB Intl. Press, Wallingford, pp. 299-338. 2002.

16. Phillips P.A.; Faber, B.A.; Morse, J.G.; Hoddle, M.S.; UC IPM Pest Management Guidelines: Avocado. Oakland: Agriculture and natural resources, university of California, 2010. (UC ANR Publication, 3436).

17. White, T. J; Bruns, T; Lee, S.; Taylor, J. Amplification and direct sequencing of fungal ribosomal RNA genes for phylogenetics. In: Innis, M. A, Gelfand, D.H.; Sninsky, J. J.; White, T. J. (Eds). PCR Protocols: a guide to methods and applications. New York: Academic Press, 1990, p. 315-322. 